\section{Raízes}

Vol. 22, $\mathrm{N}^{0} 01$, jan.-jun./2003

Trabalho recebido em 05/09/2003

Aprovado para publicação em $13 / 02 / 2004$
Márcio Caniello

Doutor em Sociologia e Professor do Departamento de Sociologia e Antropologia da UFCG

\title{
Os 25 aNOS DA PÓS-GRADUAÇÃo EM SOCIOLOGIA NO CENTRO DE HUMANIDADES
}

\author{
TwENTy YEARS of POST-GRADUATION IN SOCIOLOGY \\ AT THE CENTRO DE HUMANIDADES
}

As atividades de pós-graduação no Centro de Humanidades da Universidade Federal de Campina Grande ${ }^{1}$ iniciaram-se em março de 1977, com a fundação do Curso de Mestrado em Sociologia, iniciativa de um grupo de professores do Departamento de Sociologia e Antropologia da Universidade Federal da Paraíba - Campus II, sediado em Campina Grande ${ }^{2}$. Essa ação refletia os esforços empreendidos pelo professor Lynaldo Cavalcanti de Albuquerque ${ }^{3}$ em favor da expansão da pós-graduação na Universidade Federal da Paraíba, uma das principais diretrizes de seu prolífico reitorado, durante o qual foram criados dezenove Cursos de Mestrado e um de Doutorado.

O Curso de Mestrado em Sociologia começou a funcionar no primeiro semestre de 1977 , antes mesmo de ser regulamentado pelo Conselho Universitário, com o oferecimento de três disciplinas (Teoria Sociológica, Metodologia Científica e Estatística I) para a primeira turma de dez alunos selecionados, sete dos quais seriam titulados Mestres ${ }^{4}$. Em 30 de dezembro de 1977, o reitor da UFPB, dando provimento à deliberação do CONSUNI tomada na reunião do dia 30 de novembro do mesmo ano, assi- nou a Resolução no 214/77, a qual criava o Programa Integrado de Pós-Graduação em Economia e Sociologia com dois Mestrados, tendo como respectivas áreas de concentração Economia Rural e Sociologia Rural.

Embora funcionando coordenada e cooperativamente, os dois Mestrados não chegaram a constituir um "Programa Integrado" e, desde a fundação, os Cursos mantiveram sua autonomia acadêmica e administrativa, situação que seria oficializada através das Resoluções 52/79 e 80/ 79 , do CONSEPE, as quais regulamentaram, respectivamente, a reestruturação do currículo e o Regulamento Interno do Curso de Mestrado em Sociologia, aprovadas no âmbito do Colegiado do Curso em $1^{\circ}$ de junho de 1979, e no Conselho do Centro de Humanidades no dia 12 de junho do mesmo ano.

O primeiro relatório anual do Curso de Mestrado em Sociologia enviado à CAPES, referente ao segundo semestre de 1977 e ao primeiro semestre de 1978, demonstra que no processo seletivo da turma de 1978 se inscreveram 27 candidatos, sendo 7 docentes de ensino superior (um da UFPB e seis de outras IES) e 20 não docentes. Foram

${ }^{1}$ A Universidade Federal de Campina Grande (UFCG) foi criada a partir de desmembramento da Universidade Federal da Paraíba (UFPB) pela Lei n ${ }^{\circ}$ 10.419, de 9 de abril de 2002, ficando composta pelos campi de Campina Grande, Patos, Sousa e Cajazeiras.

${ }^{2}$ A primeira reunião do Colegiado do Curso, à qual compareceram as professoras Gisélia Franco Potengy (coordenadora do Curso no biênio 1977-1979), Ignez Paulilo, Dorothy Azevedo, Nancy Dione Loy e o professor Constantino Soares Souto, foi realizada no dia 25 de março de 1977.

${ }^{3}$ Reitor da UFPB entre 1976 e 1978.

${ }^{4}$ Os alunos titulados da primeira turma foram: Francisca Bezerra Marques, Geraldo Targino da Silva, Luiz Gonzaga Melo, Mirian Sivini Ferreira, Marlúcia Sales de Morais, Maria do Socorro Pereira dos Santos e Wilma Fernandes Grossman Cabral. 
aprovados 12 candidatos (7 docentes e 5 não docentes), o que, somando-se aos alunos da turma de 1977, dava um total de 22 alunos matriculados ${ }^{5}$ No mesmo período havia 20 professores vinculados ${ }^{6}$, quatro deles em afastamento para capacitação. Segundo o relatório anual 1978/1979, os docentes e seus respectivos orientandos estavam agrupados em 4 linhas de pesquisa, a saber: "Agricultura e capitalização no campo" (2 projetos de pesquisa), "A pequena produção" (1 projeto de pesquisa), "A problemática agrária e os mecanismos de poder" (3 projetos de pesquisa) e "Estudos rural-urbano" (2 projetos).

A leitura do Anexo II do segundo relatório enviado à CAPES demonstra que, embora novo, o Curso demonstrava grande vitalidade, seja na perspectiva acadêmica, através da promoção de seminários com professores convidados - entre os quais Octávio Ianni, Heleieth Saffioti, Maria Nazareth Wanderley, Roque Laraia e José Graziano da Silva, que participaram de eventos no primeiro semestre de 1978 —, seja no engajamento da pesquisa através de uma postura claramente voltada para a solução dos problemas concretos da realidade regional:

"O Curso oferece a partir do terceiro semestre distintas opções para que os alunos adquiram conhecimento mais profundo numa área determinada ou em torno de alguma problemática sócio-econômica ou política regional. Esta fase do processo de formação do mestrando tem por objetivo vincula-lo a um campo concreto." (grifo no original)
Pode-se dizer, com efeito, que desde então as atividades da pós-graduação em Sociologia do Centro de Humanidades se caracterizariam exatamente por esse duplo objetivo: buscar a excelência acadêmica e encontrar vias para a transformação da dura realidade social brasileira, levada ao seu paroxismo no Nordeste. Ora, formado no período de distensão do regime militar, o "Mestrado em Sociologia Rural” como ficaria conhecido nacionalmente, abrigara um conjunto de professores de alto nível, muitos deles voltando do exílio, outros tantos saindo do ostracismo forçado pelo regime de exceção, e o espírito crítico e o compromisso com a transformação da sociedade brasileira daqueles jovens profissionais, associados à experiência e ao conhecimento da realidade nordestina dos professores do Curso de Sociologia e Política da antiga FACE criado em $1962^{7}$, favoreceria a formação de um ambiente bastante vivo na pós-graduação do $\mathrm{CH}$.

Entre 1979, quando a primeira dissertação foi defendida ${ }^{8}$, e 1984, o Curso de Mestrado em Sociologia consegue manter uma ótima média nas avaliações efetuadas pela CAPES e obtém o conceito "B" nas avaliações de 1979/1980, 1982 e 1984 e “B+" em 1983, o mais alto obtido na sua história. Há que se ressaltar, com efeito, que no triênio 1982-1984 o Curso de Mestrado em Sociologia Rural, então coordenado pelo professor Charles Michel Marie Joseph Beylier ${ }^{9}$ só era superado na avaliação da CAPES pelos Programas de Pós-Graduação em Sociologia do IUPERJ, da UnB e da USP, to- 
dos com conceito "A" (Cf. CAPES, 1996: 49).

De fato, a Ficha de Avaliação de 1983 concluía que "O Curso [estava] em expansão e em franco processo de consolidação" (CAPES, 1984: 4), o que se sustentava pela boa avaliação em todos os aspectos considerados. Quanto ao corpo docente, verificou-se "considerável avanço na qualificação, quase dobrando o número de doutores: de 8 para 14" e no "progresso apreciável" em relação a especialistas na área de concentração do Curso: "14 especialistas com Sociologia Rural e 7 em Sociologia”, dos quais 9 eram doutores (Cf. CAPES, 1984: 1). No que se refere à estrutura curricular, observou-se "adequação e coerência” em relação à área de concentração do Curso e os consultores destacaram "o alto grau de coerência” dos 6 projetos de pesquisas em desenvolvimento, todos "sobre aspectos substantivos da área de estudos” (Cf. CAPES, 1984: 2). No que tange à titulação dos alunos, também foram verificados avanços importantes: oito dissertações defendidas em 1983, mais do que o total de dissertações defendidas nos cinco anos decorridos desde a criação do Curso (Figura 1), com um tempo médio de 58 meses (Figura 2), índice "dentro da média geral” (Cf. CAPES, 1984: 3).
Também no que se refere à produção docente, os indicadores eram bastante alentadores, pois no biênio 1982/1983 foram publicados três livros e trinta artigos (Cf. CAPES, 1984: 3), o que refletia o vigor acadêmico e científico do Curso, impulsionado pela publicação, a partir do segundo semestre de 1982, da Revista Raízes, periódico semestral editado em conjunto com o Curso de Mestrado em Economia, e com o lançamento, em 1983, dos Cadernos Brasil em Debates, revista dedicada à circulação de trabalhos de professores, alunos e pesquisadores vinculados ao Mestrado e ao Departamento de Sociologia e Antropologia do Centro de Humanidades, apresentados nos "Seminários Brasil em Debates", promovidos semanalmente (Cf. Giuliani, Cavalcanti e Melo, 1987: 1; CMS, 1987a: 6).

Na apresentação do primeiro número de Raízes, os diretores da Revista resumem o dinamismo do quadro acadêmico que justificara não somente o lançamento do periódico, mas a própria fundação dos Mestrados em Sociologia e Economia Rural:

"Nos últimos anos, vários estudos foram publicados sobre a agricultura no desenvolvimento capitalista da América Latina e do Brasil. Após um período de produção científica fundamentalmente teórica

Figura 1

Dissertações Defendidas (1977-2002)

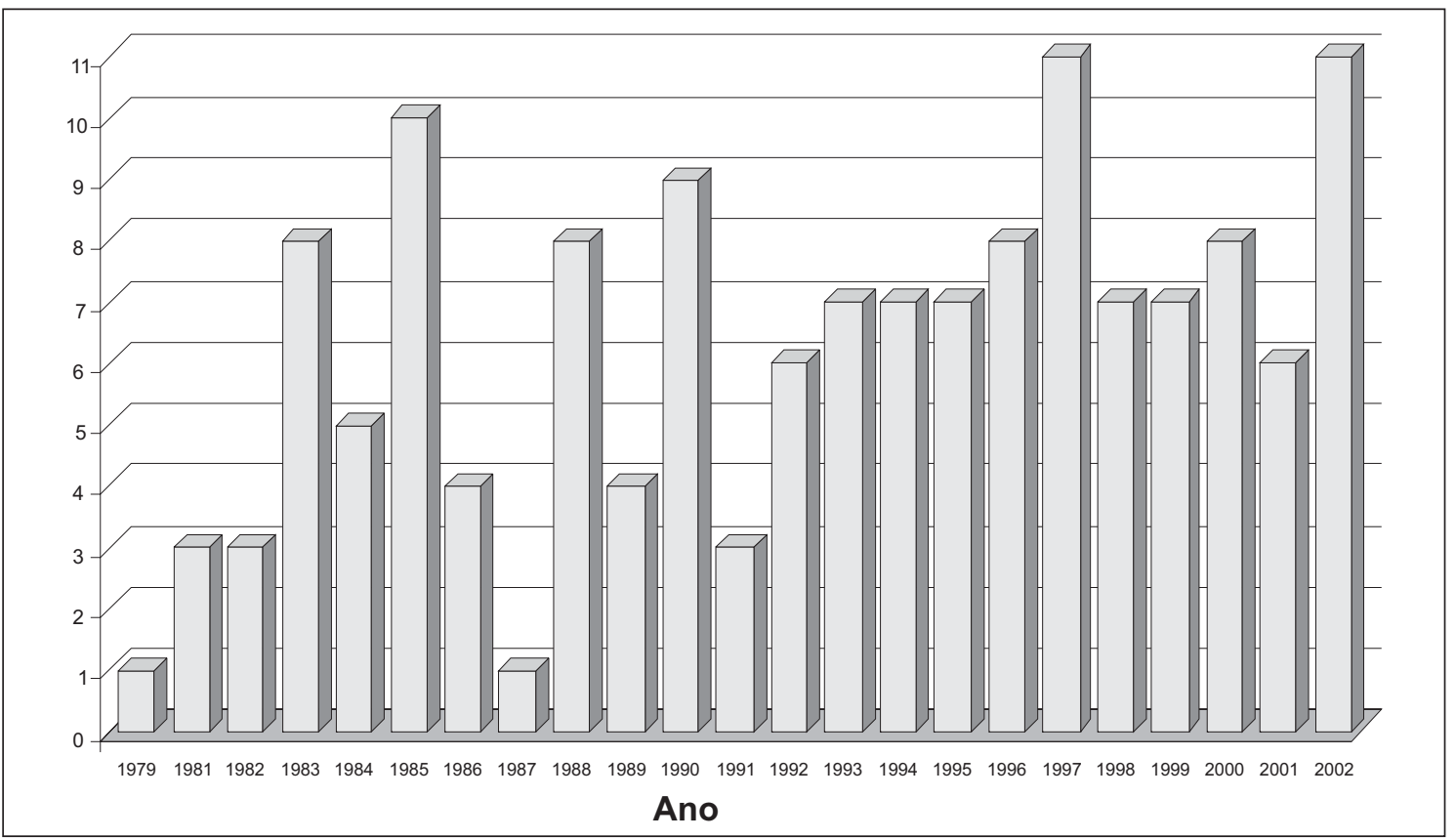

Raízes, Campina Grande, vol. 22, nº 01, p. 110-124, jan./jun. 2003 
Figura 2

Tempo Médio de Titulação (1977-2002)

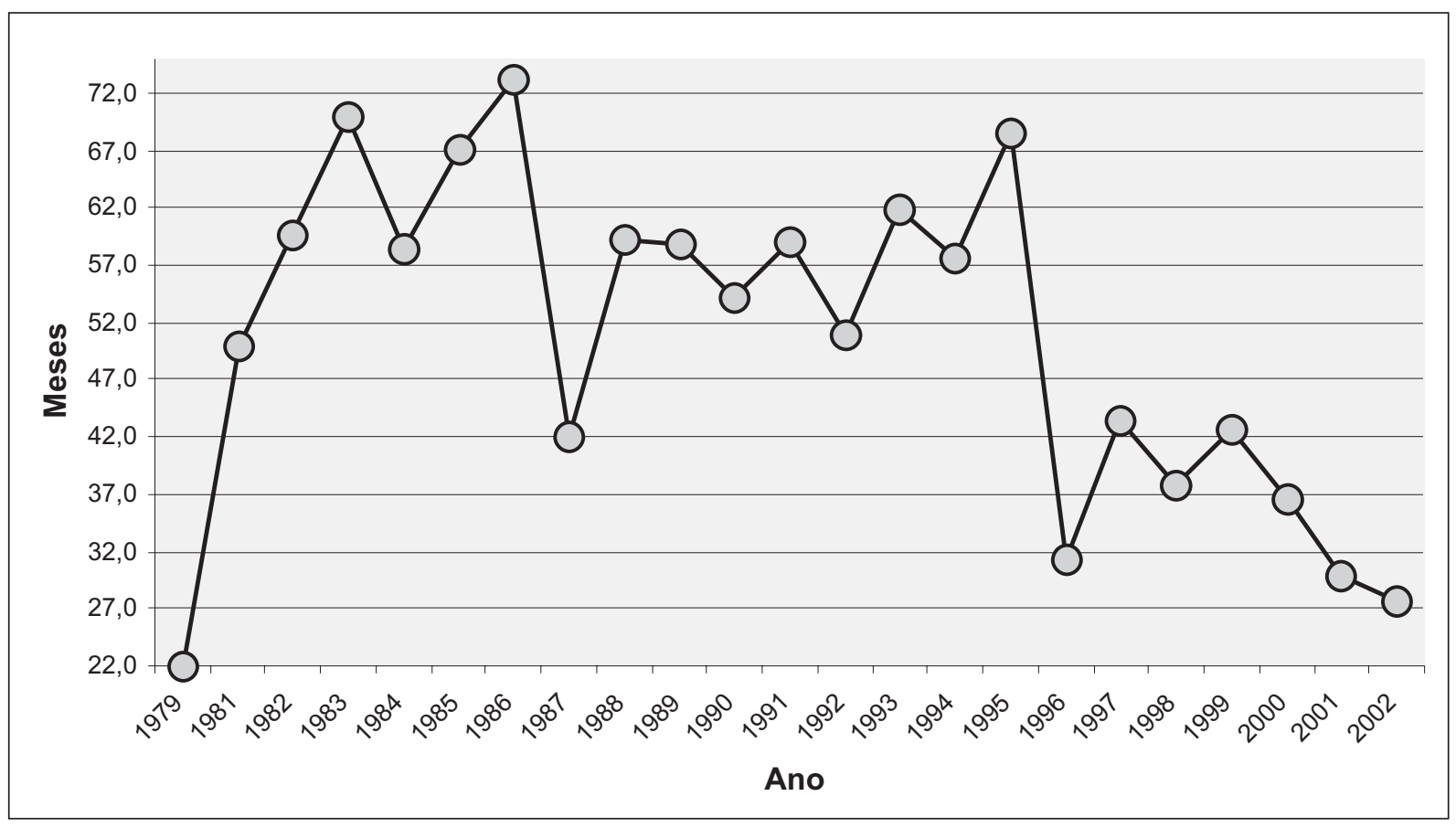

(...), os estudiosos começaram a voltar-se para uma análise mais empírica da realidade (...). A contribuição de Centros de Pesquisa como UNICAMP, CEBRAP, CEDEC, USP e Museu Nacional foi particularmente importante para o progresso das pesquisas sobre o Nordeste, tanto pelas suas publicações como pela sua participação em encontros, cursos e seminários promovidos sobre a realidade nordestina nos centros acadêmicos desta região. Um dos maiores frutos do intercâmbio científico assim iniciado foi certamente o surgimento, em algumas Universidades do Nordeste, de cursos de pós-graduação em Ciências Humanas voltados para a pesquisa e cuja produção científica começa a ser significativa." (Beylier \& Melo, 1982: 1)

Na avaliação anual de 1984, a tendência geral verificada no relatório anterior se confirmava e os consultores con- cluíram que "o processo de amadurecimento do programa avança”, inclusive pela constatação de que, embora "surpreendentemente baixa a produção técnica", a produção científica era "significativa" e que "a qualificação do corpo docente permanente [era] satisfatória, com 12 doutores, 16 mestres e mais 9 professores em programa de doutoramento" (Cf. CAPES, 1985).

As avaliações de 1983 e 1984 expressam claramente a vitalidade dos Cursos de Mestrados em Sociologia e Economia no início dos anos 80 , situação que foi extremamente favorecida pela inclusão dos programas no âmbito do Acordo CAPES/COFECUB ${ }^{10}$, efetivada pelo convênio com a Universidade Paris X (Nanterre) ${ }^{11}$. De fato, a cooperação com a França, que se perpetua até os dias de

${ }^{10}$ O Acordo CAPES/COFECUB, assinado entre os governos brasileiro e francês em $1^{\circ}$ de outubro de 1978, tinha como objetivo "favorecer a emergência ou consolidação de equipes universitárias brasileiras através da formação doutoral ou pós-doutoral no quadro de projetos de pesquisa conjuntos" (Ministére de l'Éducation Nationale, de la Recherche e de la Technologie, 1999, tradução nossa), visando, originalmente, "criar e fortalecer programas de pós-graduação em regiões como o Nordeste" (Nepomuceno, 1999).

${ }^{11}$ Os Cursos de Mestrado do Centro de Humanidades associaram-se ao Grupo de Economia e Sociologia Rurais - CNRS da Universidade Paris X (Nanterre) em torno do Projeto Sócio-Economia do Mundo Rural, sob a liderança dos professores Marcel Jollivet e Michel Gervais, que assinaram o Convênio com duração de cinco anos durante visita a Campina Grande em novembro de 1979. Este foi o primeiro projeto na área de Ciências Sociais no âmbito do Acordo e o professor 
hoje ${ }^{12}$, repercutiria fortemente na vida dos Cursos de Mestrado em três direções principais: na titulação de professores da UFPB em Universidades francesas, na formação dos alunos através de cursos e seminários ministrados por professores franceses em visita ao Brasil e no forte intercâmbio de experiências de pesquisa efetivado em diversas missões de trabalho de parte a parte.

$\mathrm{Na}$ avaliação de 1985/1986, contudo, o conceito atribuído ao Curso cai para "C", o que foi justificado pela redução de docentes permanentes, pelo aumento de docentes participantes com mestrado, pelo fluxo decrescente de alunos matriculados e pela queda na produção docente e discente (Cf. CAPES, 1987). A coordenadora de então, professora Norma Montalvo de Soler ${ }^{13}$, em recurso impetrado na CAPES admitia a queda da produção docente, mas argumentava que a redução no quadro docente fora promovida para responder às próprias orientações da agência no sentido de "enxugar o quadro de professores permanentes, considerado 'inchado' com relação à efetiva participação nas atividades do mestrado", completando que "pela primeira vez na vida do mestrado, contamos com um quadro docente que, em nossa auto-avaliação, é bem qualificado (10 doutores e 5 mestres, sem incluir os doutores participantes) e que realiza um trabalho efetivo e expressivo em todas as atividades do mestrado" (CMS, 1987b: 2).

É de se ressaltar que o quadro docente se completava com sete professores afastados cursando o Doutorado, o que projetava a formação de um contingente expressivo de professores-doutores nos anos vindouros. Por outro lado, a coordenadora demonstrava que, no que se referia à produção discente, os consultores não haviam atentado para o fato de que, embora tivesse havido um "retrocesso" (CAPES, 1987: 4) de 10 dissertações defendidas em 1985 para 4 dissertações defendidas em 1986, as 14 dissertações defendidas no biênio representavam $41 \%$ do total de dissertações defendidas nos nove anos de existência do Curso.
Seja como for, a tendência verificada em 1986 não seria revertida e, desde então, o Programa passaria a atingir tão somente a cotação "C”, o que não impediu que o Curso de Mestrado em Sociologia fosse credenciado pelo Conselho Federal de Educação em $1989^{14}$. O relator do processo, conselheiro Jacks Grinberg, valendo-se do relatório da Comissão de Consultores Científicos presidida pela professora Vilma de Mendonça Figueiredo, da Universidade de Brasília, e do relatório da visita realizada dos dias 11 e 12 de outubro de 1988 pelos professores Jorge Romano, da Universidade Federal Rural do Rio de Janeiro, e Vera Lúcia Bota Ferrante, da UNESP de Araraquara, recomendou o cadastramento do Curso, atribuindo-lhe a conceituação global "C", a partir da ponderação entre o conceito "B" concedido para o corpo docente e atividades de ensino e conceito "C" atribuído para atividades de pesquisa, produção docente, produção discente e fluxo de alunos (Cf. CFE, 1989).

Tudo indica que os problemas apontados por ocasião do credenciamento foram se agravando com o passar dos anos, pois o Curso obtém sua menor marca histórica na avaliação do biênio 1992/1993, quando recebe o conceito "C-". A Ficha de Avaliação dos Cursos de Pós-Graduação 1989/1991 aponta os quatro principais fatores que provocaram a tendência de queda que culminaria no baixo conceito da avaliação posterior: (1) o perfil do corpo docente (baixa titulação dos professores permanentes, dependência excessiva de professores colaboradores e produção docente "reduzida e insatisfatória”); (2) o fluxo da produção discente (alto tempo médio de titulação); (3) problemas de adequação no currículo e na seleção (especialmente em relação a teoria e metodologia); e (4) problemas de compatibilidade nas linhas de pesquisa (Cf. CAPES, 1992).

Segundo o relatório do Seminário de Auto-Avaliação realizado em 1991, elaborado pela coordenadora de então, professora Josefa Salete Barbosa Cavalcanti ${ }^{15}$, o ponto crí-

José Heleno Rotta foi o coordenador brasileiro do Convênio UFPB/Université Paris X entre 1979 e 1984.

12 O Convênio CAPES/COFECUB foi sucessivamente renovado por mais de 20 anos e, mesmo com sua interrupção, a cooperação com a França não teve solução de continuidade, sendo sustentada atualmente por um Convênio com o CIRAD. Na sua história de 25 anos, o Programa também estabeleceu convênios com Universidades da Inglaterra, Alemanha e Canadá.

${ }^{13}$ A professora Norma Soler foi coordenadora do Curso entre agosto de 1987 e setembro de 1989.

${ }^{14}$ Processo 23001.000789/87-91, concluído nas instâncias da UFPB em julho de 1987 e aprovado pela Câmara de Ensino Superior em sessão realizada em 31 de julho de 1989.

${ }^{15}$ A professora Salete Cavalcanti foi coordenadora do Curso entre fevereiro de 1985 e julho de 1987 e entre outubro de 1989 e julho de 1991, totalizando 41 meses no exercício da função. 
tico dessa tendência de queda foi a transferência para outros centros de vários professores-doutores credenciados no Curso, alguns deles beneficiários do Acordo CAPES/COFECUB, possibilidade aberta pela implantação da carreira única para os docentes das IFES em 1987 (Cf. CMS, 1991: 5). É de se notar que, naquele ano, comemorativo dos dez anos do Curso, um documento previa essa tendência, relacionando-a, com efeito, à própria consolidação do Curso de Mestrado em Sociologia Rural:

\footnotetext{
"À medida que o curso se fortalece, surge o interesse de outras Universidades do Sudeste e outros centros de pós-graduação da própria região Nordeste, em absorver professores vinculados ao Curso. Tal fato causa novas preocupações, relativas à renovação do quadro de professores, nos níveis exigidos pelo grau de avanço do curso" (CMS, 1987a: 9)
}

De fato, na Ficha de Avaliação dos Cursos de Pós-Graduação 1992/1993, os consultores da CAPES justificam o conceito atribuído ao Curso pelo "baixo índice de titulação do corpo docente, dependência elevada de professores participantes e não reposição da perda expressiva de professores titulados" (CAPES, 1994: 6), avaliação corroborada pela professora Maria Nazareth Baudel Wanderley que, no relatório da visita feita ao Curso em junho de 1994, concluiu que "o esvaziamento do corpo docente repercutiu profundamente sobre todo o funcionamento do Programa”, destacando, contudo, “o grande empenho dos professores que, com seu envolvimento, foram capazes de encontrar soluções, mesmo informais e não definitivas, que permitiram a continuidade do Programa." (Wanderley, 1994: 20).

Aliás, é importante ressaltar que, como advertiu a coordenadora de então, professora Ghislaine Duqué16, em documento enviado à CAPES em 1995, afora deficiências do corpo docente devidas à falta de reposição de vagas oriundas de transferências e aposentadorias - fato aliás provocado pelas próprias políticas públicas para o setor adotadas pelos governos de então - e a afastamentos para titulação, em relação aos outros critérios avaliados pelos consultores, o curso dava mostras de recuperação (Cf. CMS, 1995).

De fato, de acordo com a "síntese evolutiva" elaborada pelos consultores na Ficha de Avaliação 92/93, dos seis critérios usados como parâmetro, o Curso teve um melhor desempenho em relação aos anos anteriores em três deles (produção docente, produção discente e fluxo de alunos), não tendo havido alteração significativa em dois (atividades de ensino e atividades de pesquisa) e só piorando em relação à "caracterização do corpo docente", isto é, exatamente quanto ao contingente e à titulação dos professores efetivos (Cf. CAPES, 1994: 5). Por outro lado, a análise do quadro sinótico anexado ao parecer do conselheiro Reinilson Batista de Oliveira sobre os indicadores de desempenho dos Cursos de Pós-Graduação da UFPB ${ }^{17}$ (Cf. UFPB, 1994) revela que embora entre os 11 cursos da grande área de Ciências Humanas e Sociais Aplicadas analisados no biênio 1992/1993 o pior conceito tenha sido o do Curso de Mestrado em Sociologia Rural (C-), o seu desempenho era comparativamente bastante bom em praticamente todos os quesitos analisados: ficou em $3^{\circ}$ lugar em termos de índice de titulação de alunos $(0,15)$ e na produção de livros e capítulos (15, no total) e em $5^{\circ}$ lugar na produção de artigos em revistas nacionais (33 artigos), na relação dissertações defendidas/orientadores $(0,68)$ e na proporção de professores efetivos com doutorado (53\%). O indicador discrepante referia-se precisamente ao corpo docente: com 11 professores efetivos, era o penúltimo da lista.

Diante da crise iminente, uma vez que o Curso atingia o mais baixo patamar de conceituação para os Programas de Pós-Graduação recomendados pela CAPES, a coordenação enviou àquela agência uma Proposta de Recuperação do Curso (Cf. CMS, 1995) centrada num plano de reforma curricular e de aprimoramento das atividades de pesquisa, de maneira a melhor articular as atividades de ensino e de pesquisa, principal deficiência do Curso depois dos problemas verificados quanto ao efetivo do corpo docente, questão esta de competência de outras esferas institucionais. As medidas propostas culminavam na criação de uma nova área de concentração e pesquisa voltada ao desenvolvimento sócio-ambiental do semi-árido, com dois objetivos: "ter uma prática mais ágil e flexível de pesquisa capaz de responder às necessidades da sociedade" (CMS, 1995: 9) e a criação de um Curso de Doutorado Interdisciplinar dedicado à temática. Isto é, propunha-se o resgate do binômio que sustentara a excelência do Curso no início da década de 1980: uma política de pós-graduação pautada pelo compromisso social e pela responsabilidade acadêmica.

\footnotetext{
${ }^{16}$ A professora Ghislaine Duqué foi Coordenadora do Curso entre março de 1992 e abril de 1996, totalizando 49 meses no exercício da função.

${ }^{17}$ Processo no $23074.002427 / 94-29$.
} 
O parecer da CAPES quanto à reestruturação do Curso foi favorável: o consultor anônimo considerou a proposta de reforma curricular "bastante positiva em vários aspectos", a criação da nova área de concentração "extremamente atraente" e, embora sugerisse que a proposta da criação do Doutorado exigia "um tempo maior de maturação", concluiu seu parecer dizendo que "recomenda-se fortemente a proposta de consolidação do Curso de Mestrado em Sociologia Rural da Universidade Federal da Paraíba, Campus de Campina Grande” (CAPES, 1995).

Apesar disso, a avaliação do Curso continuava bastante adversa, o que pode ser verificado no Relatório do biênio 1994/1995, quando, entre os 20 programas avaliados pela CAPES, 6 obtiveram conceito "A", 11 o conceito "B" e apenas 3 o conceito "C": os Cursos de Mestrado da UFPB - Campina Grande e João Pessoa - e da UFRN (Cf. CAPES, 1996b). Em relação às tendências dominantes, o corpo docente foi considerado "bom", as atividades de pesquisa "adequadas" e a produção discente "boa", mas a produção docente foi considerada "fraca" e a estrutura curricular "inadequada” (Cf. CAPES, 1996a).

De fato, como observou o consultor Jorge Romano em visita ao Curso em fevereiro de 1996, "a implementação completa e formal da Reforma tem sido postergada em função de problemas com os regimentos gerais da pós-graduação e com os procedimentos da UFPB que dificultam sua aprovação" (Romano, 1996: 3). Por outro lado, contudo, a situação havia melhorado em relação ao principal problema apontado nas avaliações anteriores: embora o número de professores permanentes se mantivesse inalterado, observou-se uma diminuição na dependência de professores participantes e "uma reversão na qualificação do conjunto do corpo docente, predominando atualmente o número de Doutores (14) sobre o número de Mestres (9)" (Cf. Romano, 1996: 12-13). O consultor, todavia, não deixou de observar "o número pequeno da produção docente", embora tenha ressaltado que "no que se refere ao conjunto da produção docente, ela apresenta-se coerente com a proposta do curso e, em vários casos (...) os trabalhos realizados e os em andamento constituem uma contribuição nova ao estado do conhecimento específico no Brasil" (Romano, 1996: 22 e 24) ${ }^{18}$.
Tudo indica, com efeito, que a partir de 1997 consolidava-se o movimento de reversão na tendência de baixo desempenho do Curso de Mestrado em Sociologia verificada na Avaliação Anual de 1985/1986 e que atingira o seu ponto crítico na Avaliação Anual de 1992/1993. Em relação a isso o relatório da consultora Anita Brumer, que visitou o Curso em abril de 1998, não deixa a menor dúvida (Cf. Brumer, 1998). Senão, vejamos.

Por um lado, o Programa demonstrava conservar grande vitalidade em dois aspectos bem marcantes de sua trajetória. Primeiro, mantinha-se operante uma das vocações mais fortes e perenes do Curso de Mestrado em Sociologia Rural: a "excelente integração com a Extensão" (Brumer, 1998: 36), destacando-se a "ativa e continuada participação de professores e alunos em atividades de assessoria, acompanhamento e capacitação de lideranças de movimentos populares, de assentamentos de reforma agrária e de experiências de desenvolvimento agrícola alternativo" (Brumer, 1998: 36). Segundo, preservava-se a sua prolífica política de intercâmbio interinstitucional, seja através da cooperação com o Curso de Mestrado em Economia Rural, seja pela intensa participação dos professores nos fóruns acadêmicos nacionais, seja pela rica atividade de cooperação internacional, efetivada então pela assinatura de mais um Convênio no âmbito do Acordo CAPES/COFECUB com a Universidade de Tours (1998) e pela conclusão exitosa dos Convênios com a Universidade de Manitoba (1995-1997) e com a Universidade de Manchester (1992-1997).

Por outro lado, evidenciava-se a superação de várias dificuldades apontadas anteriormente. Por exemplo, a proposta de reestruturação do Curso, originalmente apresentada em 1995, havia sido discutida e reelaborada pelo coletivo de professores durante dois anos e era implantada em maio de 1997 com a aprovação do novo Regulamento e Currículo através da Resolução 46/97 do CONSEPE. Segundo a consultora citada, "a nova estrutura curricular amplia a flexibilidade na montagem do currículo dos alunos" (Brumer, 1998: 8), fato considerado por ela como principal causa da "redução significativa no tempo de titulação" (Brumer, 1998: 42),

\footnotetext{
${ }^{18}$ Isto é, neste que era considerado pela CAPES um dos principais pontos fracos do corpo docente do Curso, o critério da quantidade apurado pelo Relatório Anual parece ter obscurecido o critério qualitativo observado pelo consultor, contrariando, aliás, um dos pontos centrais do "formato avaliativo da CAPES”, baseado, segundo a própria Coordenação de Aperfeiçoamento de Pessoal de Nível Superior, em "diagnósticos quali-quantitativos construídos em sintonia com a comunidade acadêmica e efetivados com o concurso de pares acadêmicos" (Cf. Leite, 2002: 95).
} 
o que pode ser efetivamente verificado pela análise da Figura 2 (Cf. infra). Além disso, a consultora observava que "o curso vem mantendo um bom fluxo de alunos” (Brumer, 1998: 26) e que "a relação orientando/ orientador é equilibrada” (Brumer, 1998: 23), o que revelava, neste aspecto particular, "uma evolução positiva” (Brumer, 1998: 24).

Além disso, a transformação do Banco de Dados em Biblioteca Setorial da Pós-Graduação, com grande investimento na compra de livros e periódicos, e a montagem de um Laboratório de Informática, ações partilhadas com Curso de Mestrado em Economia e financiadas com recursos do Programa de Recuperação/Consolidação da CAPES (Cf. CAPES, 1998: 4), foram consideradas "um grande avanço” (Brumer, 1998: 44), pois, de fato, isso resolvia em grande parte os problemas de infra-estrutura apontados pelos consultores que haviam visitado anteriormente o Programa (Cf. Wanderley, 1994: 16 e Romano, 1996: 27).

Em relação ao corpo docente, o ponto mais crítico das avaliações anteriores como pudemos observar, os indícios de recuperação eram também bastante claros. É certo que o quadro permanente ainda era bastante pequeno (10 professores), mas isso era resultado da observância da orientação incisiva da CAPES quanto à exclusão das atividades de pós-graduação de docentes sem o título de doutor e da redução da dependência de professores participantes (Cf. Brumer, 1998: 14 e 20). Em contrapartida, entretanto, a consultora observava que "o curso tem tomado medidas para melhorar a qualificação” (Brumer, 1998: 21), atuando na atração de professores visitantes (dois naquela ocasião), mas principalmente investindo na capacitação dos docentes da casa, política que já vinha dando seus frutos com a integração de dois professores recém-titulados em 1996 e 1997, e com a expectativa da volta de mais 9 professores titulados até o ano de 2001 (Cf. Brumer, 1998: 15). Isto é, projetava-se um quadro permanente de 19 professores doutores com incorporações paulatinas em três $\operatorname{anos}^{19}$.

Em vista da realidade que observou, aliás com extrema acuidade, a Dra. Anita Brumer conclui seu relatório com uma recomendação categórica:

\begin{abstract}
"Apesar de nem todos os indicadores da CAPES para um curso de pós-graduação de excelência terem sido alcançados pelo Curso de Mestrado em Sociologia (Sociologia Rural) da UFPB/CG no período considerado, são evidentes os progressos feitos principalmente em termos de qualificação do corpo docente, redução do prazo de titulação dos alunos e infraestrutura física. Também é evidente a importância da continuidade do Curso de Mestrado em Sociologia (Sociologia Rural) da UFPB/CG e a necessidade da manutenção do apoio que lhe tem sido oferecido pela CAPES para sua recuperação e consolidação" (Brumer, 1998: 45-46)
\end{abstract}

Entretanto, a avaliação qualitativa de uma consultora que apreciou in loco a dinâmica de um programa de pós-graduação mais uma vez não se refletiria no famigerado conceito quantitativo guindado das estatísticas formuladas nos trâmites enredosos das avaliações anuais: o Curso de Mestrado em Sociologia Rural obteria o conceito "3" na Avaliação de 1996/1997 e a comissão de acompanhamento concluiria sua "síntese evolutiva" para o ano de 1998 considerando "sem alteração significativa" a tendência de evolução do Curso, embora considerasse "forte" o corpo docente e a produção intelectual, até então aspectos tidos como as principais fraquezas do Curso (Cf. CAPES, 1999).

Cumpria-se a profecia da Dra. Anita Brumer, que concluíra o seu relatório de visita ao Curso de Mestrado em Sociologia Rural advertindo sobre "os riscos envolvidos na atribuição de conceitos pelas comissões de avaliação da CAPES" e seu "efeito perverso sobre a capacidade de consolidação do Curso" (Brumer, 1998: 46). De fato, todo o esforço empreendido pelo coletivo de professores durante vários anos parecia desvanecido em face de uma "avaliação objetiva" que decretava a estagnação do Curso a despeito da avaliação de três consultores que testemunharam o movimento de recuperação e que recomendaram à CAPES “que se proceda oportunamente a atualização do conceito atribuído ao Programa” (Cf. Wanderley, 1994: 21; Romano, 1996: 32); Brumer, 1998: 46).

Nos arquivos do Programa de Pós-Graduação em Sociologia não há nenhum registro sobre recurso impetrado contra essa avaliação enviesada, mas o coletivo de professores não se dobraria frente às adversidades. A saída vislumbrada na época foi o investimento na idéia de criação de um Curso de Doutorado articulando parceiros

${ }^{19}$ Conservava-se, contudo, uma situação preocupante para o corpo docente: "no que diz respeito a artigos em periódicos, capítulos de livros e livros, além de pequena, a produção restringe-se a alguns docentes" (Brumer, 1998: 30). 
institucionais interessados, aliás medida recomendada por quatro consultores da CAPES que apreciaram a matéria (Cf. Wanderley, 1994: 21; CAPES, 1995; Romano, 1996: 33 e Brumer, 1998: 44). Neste sentido havia três propostas em pauta: a do "Programa de Pós-Graduação em Desenvolvimento Regional Sustentado", projeto idealizado originalmente em 1994, tinha como cerne o aprofundamento da colaboração com o Curso de Mestrado em Economia Rural e envolvia outros departamentos, inclusive do Centro de Ciências e Tecnologia (Cf. CMS, 1995: 10; Romano, 1996: 8; e Brumer, 1998: 13); a do "Curso de Doutorado em Ciências Humanas", agregando doutores de vários departamentos do Centro de $\mathrm{Hu}$ manidades (CF. CH, 1996); e a do "Programa Integrado de Pós-Graduação em Sociologia”, articulando os Cursos de Mestrado em Ciências Sociais (UFPB/JP) e em Sociologia Rural (Cf. CCHLA/CH, 1996).

Dos três projetos, o do Programa Integrado foi considerado o mais factível, pois, além de preservar o caráter disciplinar do Curso, evitando o difícil caminho de negociação de uma proposta baseada na interdisciplinaridade, o Programa de Pós-Graduação em Sociologia de João Pessoa ${ }^{20}$ já avançara na formulação de uma proposta de criação de um Doutorado próprio, pois em maio de 1999 o projeto já havia sido aprovado no Colegiado do Curso e no Conselho de Centro do CCHLA (Cf. PPGS/CMS, 1999). Isso refletia o fôlego recobrado pelo Programa de João Pessoa a partir do conceito "4" auferido pela Avaliação de 1996/1997 (Cf. CAPES, 1998b), pois se recuperava do conceito "C" obtido no biênio 1994/1995 (Cf. CAPES, 1996b), o qual interrompia a boa série de avaliações durante toda uma década, com dois conceitos "B” (1983 e 1985/1986) e quatro "B-" (1984, 1987/1988, 1989/1991 e 1992/1993) (Cf. CAPES/DAV, 1996: 49). Todavia, a proposta não avançava nas instâncias superiores da UFPB (Cf. PPGS/CMS, 1999) nem nas esferas da CAPES, pois, segundo nos informou um componente do Conselho Técnico Científico entre 1998 e 2000, o projeto só seria avalizado pela CAPES se incluísse o Curso de Mestrado em Sociologia Rural.

Sendo assim, as conversações iniciadas em 1996 evoluíram rapidamente em 1999. A primeira reunião para discussão do assunto, da qual participaram os profs.
Ariosvaldo da Silva Diniz (coordenador do PPGS), Edgard Afonso Malagodi (coordenador do CMS) ${ }^{21}$, Jacob Carlos Lima, Neide Miele e Marcos Ayala, ocorreu em 24 de maio de 1999 (Cf. PPGS/CMS, 1999) e o Regulamento e a Estrutura Curricular foram aprovadas pelo CONSEPE em reunião nos dias 10, 11 e 12 de agosto (Processo 23074.013775/99-81), entrando em vigor por força da Resolução 62/99 de 20 de dezembro do mesmo ano. A proposta foi aprovada no CTC da CAPES em 15 de dezembro daquele ano com a extinção do Curso de Mestrado em Sociologia Rural (Cadastro no SNPG $\left.n^{\circ} 24001023023 P 3\right)$ e sua fusão no Programa de Pós-Graduação em Sociologia (Cadastro no SNPG n ${ }^{\circ}$ 24001015004P3), que passou a operar nos níveis de Mestrado e Doutorado.

Embora na avaliação da proposta de criação do Curso de Doutorado em Sociologia tenha sido ressaltado que "a experiência acumulada de dois cursos de mestrado já existentes" fundamentava "as potencialidades de boa atuação do Programa reveladas na qualificação do corpo docente e na estruturação das linhas de pesquisa”, levando a comissão avaliadora "a crer que o Programa cumprirá com as exigências formais de uma proposta acadêmica" (Cf. CAPES, 1999b), a chamada fusão dos Cursos seria premiada pela CAPES com uma redução significativa na dotação do PROAP e na perda de sete bolsas de estudo.

Internamente, por outro lado, na azáfama da formulação do projeto muitas questões foram deixadas em aberto, principalmente em relação ao funcionamento prático de um Programa de Pós-Graduação em duas bases acadêmicas separadas por 130 quilômetros, nas quais se desenvolviam tradições de ensino, pesquisa e extensão próprias, procedimentos administrativos específicos e até processos eleitorais díspares. Tal foi a celeridade do encaminhamento que sequer o Regulamento do Programa foi apreciado pelo Conselho de Centro do $\mathrm{CH}$, o que provocou a abertura de um processo por parte da Pró-Reitoria de Pós-Graduação e Pesquisa em função da situação procedimental esdrúxula.

É bem verdade, todavia, que com a fusão, a atribuição do conceito 4 estendeu-se à base de Campina Grande, o que veio a tranqüilizar o coletivo de professores e alunos ao fornecer uma espécie de salvo-conduto perante a CA-

\footnotetext{
${ }^{20}$ Em 7 de março de 1996 o CONSEPE, por intermédio da Resolução n ${ }^{\circ}$ 04/96, aprovou a reestruturação do Curso de Mestrado em Ciências Sociais do CCHLA, que passou a ser denominado de Programa de Pós-Graduação em Sociologia, em nível de Mestrado.

${ }^{21}$ O prof. Edgard Malagodi foi coordenador do Curso de Mestrado em Sociologia Rural entre abril de1997 e abril de 2000 , totalizando 36 meses no exercício da função.
} 
PES, já que sua renitência em admitir o processo de recuperação do Curso de Mestrado em Sociologia Rural, apontado pelos três consultores que o visitaram durante a década de 1990, impedia que o coletivo sequer vislumbrasse a possibilidade de superação da incômoda posição de “curso em consolidação”, que perdurava desde a avaliação do biênio 1985/1986. Pior do que isso, havia o temor do rebaixamento do conceito e conseqüente fechamento do Curso, ameaça que rondava o coletivo desde 1994, por ocasião da obtenção do conceito "C-", pois, como vimos, o esforço pela adequação do Programa aos parâmetros movediços das comissões avaliadoras nunca foi inteiramente admitido pela CAPES em suas avaliações anuais, pois as "sínteses evolutivas" de suas fichas de avaliação sequer registravam um "viés” de recuperação e consolidação do Curso.

Isto é, durante anos a fio o coletivo de professores e alunos sentiu na pele o que a Dra. Anita Brumer definiu, com rara felicidade, como "efeito perverso" da atribuição de conceitos pelas comissões de avaliação da CAPES (Cf. Brumer, 1998: 46) e mais uma vez experimentava-se uma alternativa chancelada por aquela Coordenação que garantisse a sobrevivência de uma tradição de ensino, pesquisa e extensão que por mais de 20 anos havia contribuído, senão para o progresso da Sociologia brasileira, incontestavelmente para o equacionamento dos graves problemas sociais que caracterizam o Nordeste e o meio rural brasileiro.

É importante ressaltar, ademais, que a abertura do Curso de Doutorado veio a revigorar grandemente essa tradição ao firmar perspectivas de projeção nacional e internacional, o que se refletiu num aumento da demanda de candidatos nos processos de seleção, na atração de professores doutores especialistas nas temáticas do Programa, na promoção de eventos regionais, nacionais e internacionais, no fomento à cooperação com a sociedade regional, no reatamento de relações com parceiros institucionais através da negociação de novos acordos e convênios e até mesmo na abertura de parcerias interinstitucionais inéditas.

Contudo, problemas administrativos, logísticos e acadêmicos não permitiram que a fusão se consolidasse plenamente, e as duas bases do Programa funcionavam com uma relativa independência, dando continuidade, de maneira quase autônoma, a suas tradições acadêmico-administrativas particulares ${ }^{22}$. Ora, esses problemas eram pre- visíveis para uma experiência de tal ineditismo e tinha-se consciência, de parte a parte, que seriam necessários muitos esforços para superá-los. Aliás, o coletivo como um todo e as coordenações, em particular, trabalharam fortemente em prol da consolidação da fusão, mas com a criação da UFCG por desmembramento da UFPB em abril de 2002, essas dificuldades naturalmente se agravaram, pois o que era uma questão de compatibilidade entre esferas de uma mesma universidade tornou-se uma questão interinstitucional.

Seja como for, atualmente os professores e alunos que compõem a pós-graduação em Sociologia do Centro de Humanidades têm sob sua responsabilidade uma vigorosa tradição de ensino, pesquisa e extensão, cuja continuidade irão garantir seja através do aperfeiçoamento do atual modelo interinstitucional, seja através da restauração de sua autonomia acadêmico-administrativa.

Isto porque, em primeiro lugar, essa tradição tem um papel consolidado no panorama das Ciências Sociais brasileiras, particularmente no campo da Sociologia Rural; em segundo lugar, porque ela tem uma grande relevância para a sociedade regional, especialmente no equacionamento participativo de seus problemas e dilemas; e, em segundo lugar, porque todos os aspectos que indicavam a consolidação acadêmica do Curso de Mestrado em Sociologia Rural no final da década de 1990 tornaram-se ainda mais significativos.

Comecemos pela demonstração mais fácil. A interação entre os programas de pós-graduação do Centro de $\mathrm{Hu}$ manidades com a sociedade civil regional é contemporânea à própria fundação dos Cursos de Mestrado em Sociologia e Economia. De fato, no fim dos anos 70 e durante toda a década de 80 , por exemplo, quando a violência no campo era rotineira na região, havia uma intensa atividade de assessoria dos professores vinculados aos Cursos aos sindicatos rurais e à própria FETAG-PB. A experiência do CEDUP é um emblema daqueles tempos.

Por outro lado, uma tradição cultivada durante anos foi a promoção de reuniões na universidade congregando professores, alunos, pesquisadores, camponeses, lideranças de movimentos sociais e ONGs para a discussão de questões e problemas relativos ao desenvolvimento rural e regional e à mobilização e organização dos atores sociais do campo. Isso redundaria na implementação do Projeto Lua Cheia, ação extremamente elogiada pela consultora Anita

22 Essa questão, cujo teor ultrapassa os objetivos deste artigo, foi por nós analisada detalhadamente no Processo 23074.010243/03-12, fls. 35-38. 
Brumer (Cf. Brumer, 1998: 22) que ambientaria, inclusive, a construção da Articulação do Semi-Árido, que hoje conduz, por exemplo, o Programa 1 Milhão de Cisternas. A fundação da AS-PTA também é tributária dessa tradição interativa.

Outra ação bastante significativa neste sentido é a cooperação com as Organizações Não Governamentais, seja através da admissão de técnicos oriundos delas como alunos do Curso de Mestrado, seja pelas assessorias e consultorias prestadas a elas por professores e pesquisados. $\mathrm{O}$ exemplo do PATAC fala por si só: grande beneficiária dessa interação, essa ONG há muitos anos apoiada e hoje presidida pela profa. Ghislaine Duqué, recebeu recentemente três importantes prêmios por seu desempenho no equacionamento do desenvolvimento social da região semi-árida, conferidos pelo Banco Mundial, pelo Banco do Brasil e pelo NEAD.

Atualmente, um acordo de cooperação com o CIRAD tem proporcionado a implementação de outras ações importantes neste sentido, como o desenvolvimento de uma pesquisa-ação junto ao Pólo Sindical de Lagoa Seca, o apoio aos atingidos pela Barragem de Acauã e a execução do Projeto UniCampo, iniciativa de extensão que tem como objetivo implementar a Universidade Camponesa oferecendo cursos de desenvolvimento rural sustentável aos camponeses do semi-árido em campus avançados da UFCG (Cf. PPGS/CIRAD, 2002 e 2003).

Finalmente, como bem ressaltou a Dra. Anita Brumer, “desde sua fundação, o Curso de Mestrado apresenta uma

Tabela 1

Dissertações Defendidas por Linha de Pesquisa (1977-2002)

\begin{tabular}{l|c}
\hline \multicolumn{1}{c|}{ Linha de Pesquisa } & $\begin{array}{c}\text { Número } \\
\text { de Dissertações }\end{array}$ \\
\hline Sociologia Rural & 92 \\
\hline Sociologia da Cultura & 25 \\
\hline Sociologia Política & 13 \\
\hline Teoria Sociológica & 2 \\
\hline Sociologia Jurídica & 2 \\
\hline Sociologia do Desenvolvimento & 2 \\
\hline Sociologia da Educação & 2 \\
\hline Sociologia do Trabalho & 1 \\
\hline Metodologia & 1 \\
\hline \multicolumn{1}{c}{ Total } & 144 \\
\hline
\end{tabular}

Raízes, Campina Grande, vol. 22, nº 01, p. 110-124, jan./jun. 2003 vocação regional, formando profissionais de universidades, de órgãos públicos de planejamento, pesquisa e extensão, de ONGs e entidades de assessoria a movimentos sociais" (Brumer, 1998: 25). É neste ponto que a tradição de extensão se mais harmoniza com a tradição de ensino e pesquisa da pós-graduação em Sociologia do Centro de Humanidades, pois como demonstramos alhures, a sua mais destacada característica é a articulação do compromisso com a melhoria de vida da população com a construção da excelência acadêmica (Caniello, 2002).

De fato, ao analisarmos o conjunto das 144 dissertações de Mestrado defendidas entre 1977 e 2002, percebemos, em primeiro lugar, uma grande coerência em termos acadêmico-científicos, pois $67 \%$ delas — isto é, 96 dissertações — foram elaboradas no campo da Sociologia Rural (Ver Tabela 1 e Figura 3). Destacam-se como temáticas principais desse subconjunto dominante, os estudos sobre a condição camponesa (28\%), isto é, trabalhos que tratam de vários aspectos das "populações rurais livres e pobres que, desde o início do século XVIII se reproduzem no Nordeste brasileiro com base na agricultura de subsistência e no trabalho familiar" (Palacios, 1993: 42) e os estudos sobre movimentos sociais no campo e sobre o sindicalismo rural (23\%): assim, $51 \%$ das dissertações defendidas no campo da Sociologia Rural versam sobre a vida de camponeses pobres, suas lutas e suas organizações.

Completam o quadro de dissertações desse subconjunto as temáticas que definimos como questão agrária (10\%), as quais envolvem a discussão sobre a reforma agrária, assentamentos, direitos etc; estudos sobre o capitalismo no

Figura 3

Dissertações Defendidas por Linhas de Pesquisa (1977-2002)

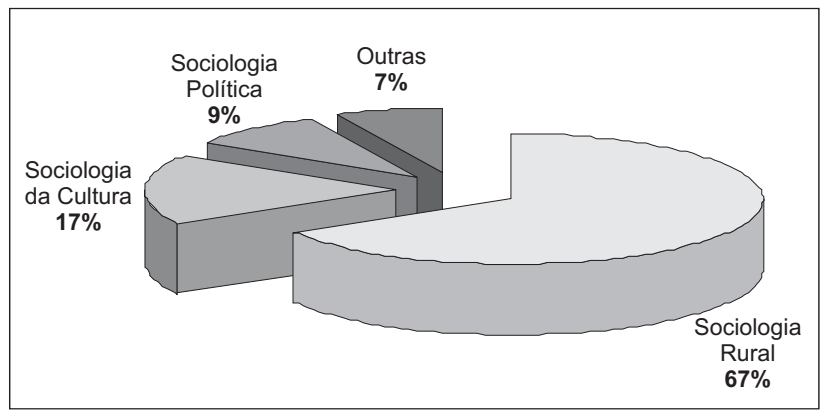


Tabela 2

Dissertações Defendidas na Linha de Pesquisa Sociologia Rural (1977-2002)

\begin{tabular}{l|c}
\multicolumn{1}{c|}{ Temática } & $\begin{array}{c}\text { Número de } \\
\text { Dissertações }\end{array}$ \\
\hline Condição camponesa & 26 \\
\hline Movimentos sociais e sindicalismo rural & 22 \\
\hline Questão agrária & 10 \\
\hline Capitalismo no campo e assalariados rurais & 8 \\
\hline Ensino, extensão e comunicação rural & 5 \\
\hline Estudos de gênero & 4 \\
\hline Outros & 21 \\
\hline \multicolumn{1}{c|}{ Total } & 96 \\
\hline
\end{tabular}

campo e assalariados rurais (8\%), estudos sobre ensino, extensão e comunicação rural (5\%) e estudos de gênero (4\%) (Ver Tabela 2 e Figura 4).

Enfim, no que se refere aos indicadores de consolidação acadêmica, é incontestável, por exemplo, a recuperação do corpo docente, pois, de fato, atualmente o Programa de Pós-Graduação em Sociologia do Centro de Humanidades conta com 16 doutores, entre professores credenciados e colaboradores ${ }^{23}$, os quais são responsáveis por 34 alunos (13 doutorandos e 21 mestrandos). Entre 2003 e 2004, três professores deverão retornar às atividades na UFCG portanto o título de doutor em Sociologia ou Antropologia.

Em relação à produção dos professores, houve também um progresso apreciável, pois, em 2002 foram publicados 12 artigos, 30 capítulos de livros, 4 livros e 3 coletâneas e uma infinidade de resumos e trabalhos completos em Anais de Congressos, dados que deverão constar do próximo relatório a ser enviado à CAPES.

Em relação à produção discente ${ }^{24}$, considerando-se o número de dissertações defendidas anualmente (Ver Tabela 1), pode-se identificar dois grandes momentos na história do PPGS. No primeiro momento que vai de 1979,
Figura 4

Dissertações Defendidas na Linha de Pesquisa Sociologia Rural (1977-2002)

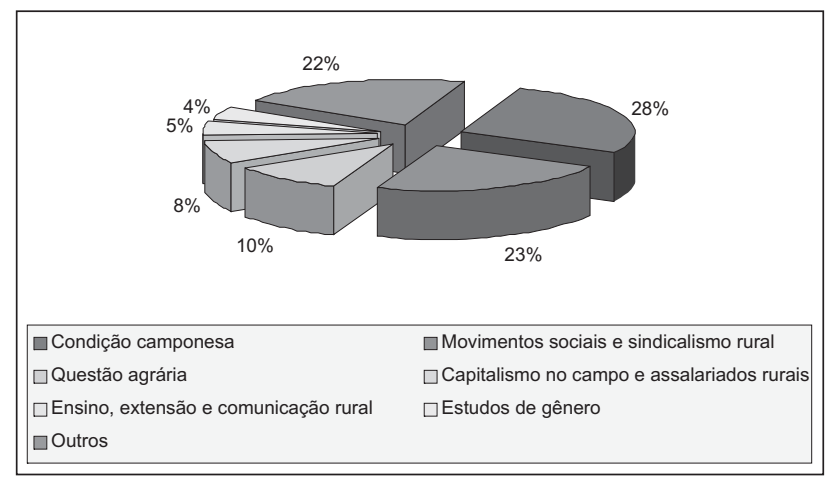

ano da primeira dissertação defendida, até 1991 foram titulados 59 mestres. Esse período é caracterizado por uma certa irregularidade no número de titulados, que varia de um mínimo de 01 mestre (1979 e 1987) a um máximo de 10 mestres (1995), o que se reflete numa baixa média anual, calculada em 4,92 titulados/ano.

O segundo período, que vai de 1992 a 2002, caracteriza-se por um aumento significativo no número de titulados (85 até a presente data), por uma maior regularidade na distribuição anual de defesas, variando de um mínimo de 06 mestres (1992 e 2001) a um máximo de 11 mestres (1997 e 2002), o que redunda, evidentemente, numa sensível alta na média anual, que, até o momento, atingiu o patamar de 7,7 titulados/ano. Confirmando-se a agenda de defesas de dissertações para o ano de 2003, o total de titulados no período deverá ser de 98 mestres, o que elevará a média anual para 8,2 titulados/ano, o que é um bom número, considerando-se que as turmas de Mestrado são compostas, em média, por 10 alunos. Até março de 2004, três alunos orientados por professores vinculados ao PPGS - UFCG deverão obter o título de doutor.

Portanto, dos 144 mestres formados pelo PPGS UFCG até a presente data, 59\% defenderam as dissertações entre os anos de 1992 e 2002, o que indica que o Pro-

${ }^{23}$ Professores credenciados: Deolinda Maria de Sousa Ramalho, Durval Muniz de Albuquerque Jr., Edgard Afonso Malagodi, Elizabeth Christina de Andrade Lima, Ghislaine Duque, Jean-Philippe Tonneau (professor visitante), Lemuel Dourado Guerra Sobrinho, Magnólia Gibson Cabral da Silva, Márcio de Matos Caniello, Marilda Aparecida de Menezes, Olívio Alberto Teixeira, Paulo Ortiz Rocha de Aragão e Rodrigo de Azeredo Grünewald. Professores colaboradores: Benedita Edina de Lima Cabral, Fábio Gutemberg e Gervácio Batista Aranha.

${ }^{24}$ Os dados de produção discente do período pós-fusão referem-se apenas às dissertações defendidas sob a orientação de professores vinculados ao PPGS do Centro de Humanidades. 
grama vem otimizado a média anual de titulados. De fato, tomando-se os últimos cinco anos como parâmetro e considerando-se a agenda de defesas para este ano, estima-se que a média de titulados atingirá a marca de 9 titulados/ ano para o período ao final de 2003.

No que se refere ao tempo médio de titulação (TMT), um dos principais parâmetros utilizados pela CAPES para avaliar a atuação dos Programas de Pós-Graduação e definir as dotações de bolsa de estudos e do PROAP, o desempenho do PPGS - UFCG é bastante positivo (Figura 2). Nesse aspecto também podemos identificar dois "momentos" que ilustram o esforço coletivo de professores e alunos no sentido da adaptação das práticas acadêmicas às exigências da CAPES. De fato, se entre $1979 \mathrm{e}$ 1995 o TMT era de 57,1 meses, entre 1996 e 2002, essa cifra despenca para 35,6 meses. Nos últimos dois anos, o TMT no Programa de Pós-Graduação em Sociologia do Centro de Humanidades tem permanecido abaixo de 30 meses, estando no escopo das determinações da CAPES.

Portanto, considerando-se o desempenho do PPGS UFCG em termos de titulação de alunos, pode-se dizer que há uma clara tendência pelo crescimento do contingente anual de titulados e pela otimização e estabilização do tempo médio de titulação, o que é um bom indicador da efetividade do Programa e do seu compromisso com as diretrizes traçadas pela Coordenação de Aperfeiçoamento do Pessoal de Nível Superior.

Portanto, ao contemplarmos os 25 anos da pós-graduação em Sociologia do Centro de Humanidades da Universidade Federal de Campina Grande pudemos observar a perenidade de uma tradição de ensino, pesquisa e extensão construída pela garra de um coletivo de professores e alunos que, a despeito de todas as vicissitudes e, especialmente, do "efeito perverso" da atribuição de conceitos pelas comissões de avaliação da CAPES (Cf. Brumer, 1998: 46), mantém uma prática baseada na busca da excelência acadêmica e no compromisso com a melhoria de vida da população, em particular dos camponeses pobres do Nordeste brasileiro. Oxalá essa tradição viceje ainda por muitos anos.

\section{REFERÊNCIAS BIBLIOGRÁFICAS}

BEYLIER, Charles M.M.J. \& MELO, Ademir A. de. "Apresentação", Revista Raízes, Ano I, no 1, jul-dez/ 1982.

BRUMER, Anita. Relatório de Visita ao Curso de PósGraduação em Sociologia do Centro de Humanidades UFPB - Campus de Campina Grande. Porto Alegre, 1998, dat.

CANIEllo, Márcio. Os 25 anos da Pós-Graduação em Sociologia do Centro de Humanidades: balanço e perspectivas. Discurso proferido na V Semana de Ensino, Pesquisa e Extensão. Campina Grande, 2002.

CAPES. Ficha de Análise e Avaliação de Cursos de PósGraduação - $2^{\circ}$ Semestre de 1980 - $1^{\circ}$ Semestre de 1981: Curso de Mestrado em Sociologia (Sociologia Rural) — UFPB. Brasília, CAPES, 1982.

CAPES. Ficha de Avaliação dos Cursos de Pós-Graduação - 1981 (2 $2^{\circ}$ semestre) e 1982: Curso de Mestrado em Sociologia - UFPB (Campina Grande). Brasília, CAPES, 1983.

CAPES. Ficha de Avaliação dos Cursos de Pós-Graduação - 1983: Curso de Mestrado em Sociologia Rural UFPB. Brasília, CAPES, 1984.

CAPES. Ficha de Avaliação dos Cursos de Pós-Graduação - 1984: Curso de Mestrado em Sociologia Rural UFPB. Brasília, CAPES, 1985.

CAPES. Ficha de Avaliação dos Cursos de Pós-Graduação - 1985/86: Curso de Mestrado em Sociologia Rural - UFPB. Brasília, CAPES, 1987.

CAPES. Ficha de Avaliação dos Cursos de Pós-Graduação - 89-91: Curso de Mestrado em Sociologia Rural UFPB - Campus II. Brasília, CAPES, 1992.

CAPES. Ficha de Avaliação dos Cursos de Pós-Graduação - 92-93: Curso de Mestrado em Sociologia Rural UFPB - Campus II. Brasília, CAPES, 1994.

CAPES. Parecer sobre a Proposta de Recuperação do Curso de Mestrado em Sociologia Rural da Universida- 
de Federal da Paraíba, Campus de Campina Grande. Brasília, 1995, dat.

CAPES. Avaliação da Pós-Graduação: síntese dos resultados (1981-1993). Brasília, CAPES/DAV, 1996.

CAPES. Ficha de Avaliação de Programa de Pós-Graduação - 94-95: Curso de Mestrado em Sociologia Rural -UFPB - Campina Grande. Brasília, CAPES, 1996a.

CAPES. Relatório Final da Área de Sociologia e Ciências Sociais — Avaliação do Biênio 1994/1995. Brasília, CAPES, 1996b.

CAPES. Memória da Pós-Graduação - Sistema de Avaliação: Síntese de Indicadores (ano base 1997) - Curso de Mestrado em Sociologia Rural - UFPB / Campina Grande. Brasília, CAPES, 1998.

CAPES. Avaliação dos Programas de Pós-Graduação: síntese da avaliação da área de Sociologia, 1996/1997. Brasília, CAPES, 1998b.

CAPES. Avaliação do Programa 24001023023P3 - Sociologia Rural - UFPB /C.G. - período 1998. Brasília, CAPES, 1999.

CAPES. Ficha de Avaliação da Proposta: Curso Sociologia / UFPB, nível Doutorado. Brasília, CAPES, 1999b.

CAPES. Ficha de Avaliação do Programa - Período de Avaliação: 1998/2000 — Área de Avaliação: Sociologia Programa: 24001015004P3 - SOCIOLOGIA / UFPB/ J.P. Brasília, CAPES, 2001.

CAPES. Ficha de Avaliação do Programa - Período de Avaliação: 2001/2003 (Avaliação Continuada) —Área de Avaliação: Sociologia — Programa: 24001015004P3 SOCIOLOGIA / UFPB/J.P. Brasília, CAPES, 2002.

CCHLA / CH. Programa Integrado de Pós-Graduação em Sociologia: projeto de integração. João Pessoa e Campina Grande, CCHLA / CH, 1996, dat.

CFE. Credenciamento do Curso de Mestrado em Sociologia — área de concentração Sociologia Rural - ministrado no Centro de Humanidades, UFPB - Campus II. Brasília, Conselho Federal de Educação, 1989.
CH. Programa de Pós-Graduação e Pesquisa do Centro de Humanidades. Campina Grande, Centro de Humanidades, 1996, dat.

CMS. Distribuição do ingresso e saída dos alunos do Curso de Mestrado em Sociologia Rural — período 1977 a 1990. Campina Grande, CMS, s/d, dat.

CMS. Reconhecimento do Curso de Mestrado em Sociologia - Área de Concentração em Sociologia Rural. Campina Grande, CMS, 1979.

CMS. Perfil do Curso de Mestrado em Sociologia UFPB - Centro de Humanidades. Campina Grande, CMS, 1987a, dat.

CMS. Recurso à avaliação do Mestrado em Sociologia Rural feita pela comissão de consultores científicos da CAPES relativa ao período 1985/86. Campina Grande, CMS, 1987b, dat.

CMS. Seminário de Auto-Avaliação: relatório do grupo I. Campina Grande, Curso de Mestrado em Sociologia, 1991.

CMS. Proposta de Recuperação do Curso. Campina Grande, Curso de Mestrado em Sociologia, 1995.

GIULIANI, G.M., CAVALCANTI, J. S. B. e MELO, J. C., "Apresentação", Cadernos Brasil em Debate. Campina Grande, Curso de Mestrado em Sociologia Rural, 1987.

LEITE, Denise. "Sistemas de avaliação das instituições de ensino superior", in Maria Susana Arrosa Soares (org.), A educação superior no Brasil. Brasília, CAPES, 2002.

LIMA, Marcio Javan Camelo de. Neoliberalismo e Sociologia: uma análise dos egressos do Curso de Ciências Sociais UFPB/CG - 1980/1999. Dissertação de Mestrado. Campina Grande, Programa de Pós-Graduação em Sociologia, 2002.

MEC. Distorções da Pós-graduação. Brasília, Assessoria de Comunicação do Ministério da Educação, 2003.

MINISTÈRE DE L'ÉDUCATION NATIONALE, DE LA RECHERCHE ET DE LA TECHNOLOGIE. Vingt ans de coopération universitaire. www.education.gouv.fr/ 
discours/1999/bresilb.htm (acesso em 10/07/03).

NEPOMUCENO, Bebel. Acordo CAPES/COFECUB comemora 20 anos. ww2.uerj.br/ emquest/emquestao05/ cofecub.htm (acesso em 10/07/03).

PALACIOS, Gullermo. "Campesinato e historiografia no Brasil: comentários sobre algumas obras notáveis", Boletim Informativo Bibliográfico de Ciências Sociais, n ${ }^{\circ} 35$, $1^{\circ}$ semestre de 1993. Rio de Janeiro, ANPOCS.

PPGS/CIRAD. Políticas públicas e instituições de apoio às agriculturas familiares. Relatório de Progresso. Campina Grande, 2002, dat.

PPGS/CIRAD. Projeto UniCampo: por uma universidade camponesa. Projeto de Extensão. Campina Grande, 2003, dat.

PPGS/CMS. Proposta do Doutorado em Sociologia: memória da reunião das coordenações dos Mestrados em Sociologia. João Pessoa e Campina Grande, CMCS / CMS, 1999, dat.

ROMANO, Jorge O. Relatório de visita ao Mestrado em Sociologia com área de concentração em Sociologia Rural - Universidade Federal da Paraíba - Campus de Campina Grande. Rio de Janeiro, 1996, dat.

UFPB. Desempenho dos Cursos de Pós-Graduação. Campina Grande, UFPB/PRAI/Coordenação Setorial de Pós-Graduação e Pesquisa, 1982.

UFPB. Indicadores de funcionamento e desempenho: Cursos de Mestrado e Doutorado (1987-1993). João Pessoa, UFPB/Pró-Reitoria de Pós-Graduação e Pesquisa, 1994.

UFPB. Programa de Avaliação Institucional: Dossiê Curso de Mestrado em Sociologia Rural. João Pessoa, UFPB/ Pró-Reitoria de Pós-Graduação e Pesquisa, 1996.

WANDERLEY, Maria Nazareth Baudel. Relatório da visita ao Mestrado em Sociologia da Universidade Federal da Paraíba - Campus de Campina Grande. Campinas, 1994, dat. 